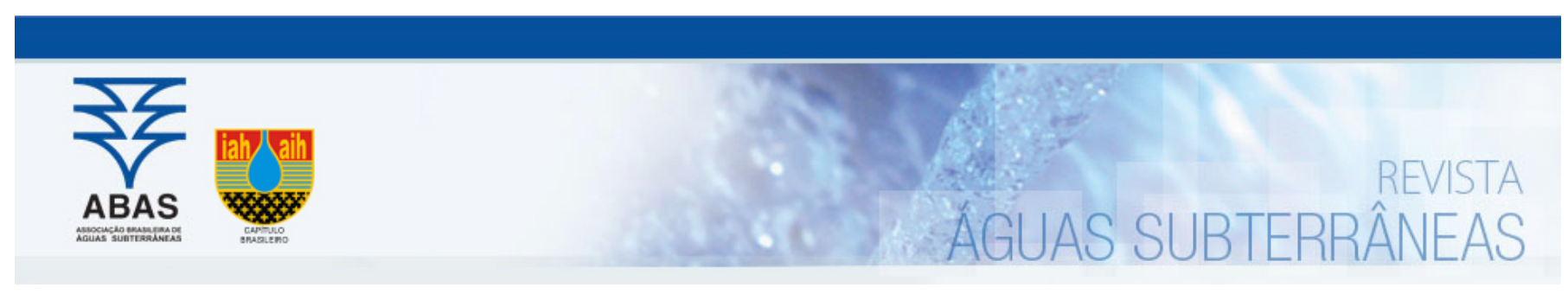

Artigos

\title{
Avaliação da aplicação de vinhaça em solo arenoso da Formação Rio Claro
}

\section{Evaluation of the application of vinasse in sandy soil of the Rio Claro Formation}

\author{
Thelma Maria Ferreira1; Miguel Angel Alfaro Soto1,2 ; Hung Kiang Chang1, 2, $3 \bowtie$ \\ ${ }^{1}$ Laboratório de Estudos de Bacias (LEBAC), UNESP - Campus de Rio Claro, SP. \\ 2 Centro de Estudos Ambientais (CEA), UNESP - Campus de Rio Claro, SP. \\ 3 Departamento de Geologia Aplicada (DGA), UNESP - Campus de Rio Claro, SP.
}

\section{$\triangle$ thelma ferreira geo@yahoo.com.br, alfaro@rc.unesp.br, chang@rc.unesp.br}

Resumo

Palavras-chave:

Cana-de-Açúcar.

Norma Técnica P 4.231/2015.

Ensaios de Coluna.

Contaminação de Solo e Água Subterrânea.

Hidrogeologia de Contaminantes.

Keywords:

Sugar Cane.

Technical Standard P 4.231/2015.

Column Tests.

Soil and Groundwater Contamination.

Hydrogeology of Contaminants.

Revisado por pares.

Recebido em: 27/08/2018.

Aprovado em: 21/11/2018.

O uso da vinhaça na fertilização de cana-de-açúcar, embora seja uma prática aceita, deve ser realizado de forma controlada, sendo regulamentado no Estado de São Paulo pela Companhia Ambiental do Estado de São Paulo - CETESB, a partir da Norma Técnica P 4.231/2015. Nesse contexto, o estudo teve como objetivo avaliar o potencial contaminante da vinhaça quando aplicada na dosagem calculada pela referida norma e em dosagens superiores. Para tanto, foram realizados ensaios laboratoriais de percolação a carga constante em colunas com amostras de solo arenoso da Formação Rio Claro. Essas amostras foram previamente infiltradas com as doses de $0 \mathrm{~m}^{3} / \mathrm{ha}$ (testemunho), $55 \mathrm{~m}^{3} / \mathrm{ha}$ (equivalente à dose máxima permitida), $80 \mathrm{~m}^{3} / \mathrm{ha}$ 400 e $800 \mathrm{~m}^{3} / \mathrm{ha}$. A aplicação dessas doses permitiu a avaliação de seus efeitos nos parâmetros hidráulicos do solo estudado e a possível geracão de diferentes graus de contaminação no efluente percolado. Os resultados indicaram que a aplicação das doses de 55 e $80 \mathrm{~m}^{3} /$ ha não trouxe nenhuma alteração significativa quanto à condutividade hidráulica saturada e que houve um aumento na capacidade de retenção do solo, fator positivo quanto à fertilidade do solo e aspectos ambientais. Entretanto, com a aplicação de doses elevadas (400 e $800 \mathrm{~m}^{3} / \mathrm{ha}$ ), além da redução da condutividade hidráulica, observou-se uma queda progressiva na capacidade de retenção do solo, implicando em perdas por lixiviação e, consequentemente, possível comprometimento da qualidade das águas subterrâneas.

Abstract

The use of vinasse in the fertilization of sugarcane, although it is an accepted practice, must be accomplished in a controlled manner, being regulated in the State of São Paulo by the Companhia Ambiental do Estado de São Paulo (CETESB) through Technical Standard P 4.231/2015. In this context, to evaluate the contaminant potential of vinasse when applied at the dosage calculated by the mentioned standard and higher dosages, constant load percolation tests were carried out in columns with samples of sandy soil from the Rio Claro Formation. These samples were previously infiltrated with doses of $0 \mathrm{~m}^{3} / \mathrm{ha}$ (control), $55 \mathrm{~m}^{3} / \mathrm{ha}^{2}$ (equivalent to the maximum dose allowed), $80 \mathrm{~m}^{3} / \mathrm{ha}, 400$ and $800 \mathrm{~m}^{3} / \mathrm{ha}$. The application of these doses allowed the evaluation of its effects on the hydraulic parameters of the studied soil and the possible generation of different degrees of contamination in the percolated effluent. The results indicated that the application of 55 and $80 \mathrm{~m}^{3} /$ ha doses did not bring any significant changes in the saturated hydraulic conductivity but there was an increase in the retention capacity of the soil, which is a positive factor regarding soil fertility and environmental aspects. However, with the application of higher doses ( 400 and $800 \mathrm{~m}^{3} /$ ha), in addition to reduction of hydraulic conductivity, a progressive fall in the soil retention capacity was observed, which implies losses due to leaching and, consequently, can compromise the quality of groundwater.

DOI: http://dx.doi.org/10.14295/ras.v32i3.29208

\section{INTRODUÇÃO}

O Brasil é o maior produtor mundial de cana-de-açúcar sendo estimada para a safra 2018/19 uma produção de 625,96 milhões de toneladas a serem colhidas em uma área de 8,61 milhões de hectares (COMPANHIA NACIONAL DE ABASTECIMENTO, 2018). Diretamente relacionada à produção de cana-de-açúcar, está a geração de vinhaça, que é um dos efluentes da produção sucroalcooleira, destacando-se pelo grande volume produzido, por possuir alto poder poluente e pelo alto valor fertilizante.

A composição da vinhaça é caracterizada por alta carga orgânica e potássio, além da presença significativa de cálcio, fósforo, sódio, magnésio, enxofre e sulfato. No entanto, sua composição é muito variável, de modo que seus efeitos no solo também variam, podendo alterar inclusive seus parâmetros hidráulicos (RIBEIRO; NO- 
VAIS; BAHIA FILHO, 1983) e, consequentemente, modificar a velocidade de percolação da água e dos contaminantes presentes na solução. Dessa forma, dadas às extremas variações composicionais da vinhaça, Rodella e Ferrari (1977) e Glória (1975) ressaltam a dificuldade em estabelecer doses fixas de aplicação.

Nesse contexto, o uso da vinhaça na fertilização de cana-de-açúcar, embora seja uma prática aceita, deve ser realizado de forma controlada, sendo regulamentado no Estado de São Paulo pela Norma Técnica P 4.231, da Companhia Ambiental do Estado de São Paulo - CETESB (2015). Segundo a referida norma, as dosagens de aplicação da vinhaça deverão ser calculadas em função das necessidades da planta em relação ao potássio, considerando características do solo e, também, as concentrações de potássio no solo e na vinhaça.

Nesse cenário, no Brasil, têm sido publicados trabalhos avaliando a aplicação de diferentes dosagens de vinhaça em diferentes tipos de solo, sendo realizados diretamente em áreas de cultivo de cana-deaçúcar (GLOEDEN et al.,1991) ou em condições de laboratório (LOBATO, LIBARDI; CAMARGO, 1998 e BRITO; ROLIM, 2005). Assim, visando avaliar a problemática da utilização da vinhaça, Hassuda, Rebouças e Cunha (1990) desenvolveram um trabalho em uma áreapiloto do Aquífero Bauru com o qual concluíram que a aplicação de vinhaça na fertilização da área gerou impactos na qualidade da água subterrânea que apresentou concentrações de alumínio, cloreto, ferro, nitrogênio amoniacal, magnésio, manganês e matéria orgânica superiores aos padrões de potabilidade estando, portanto, inadequada para o consumo humano.
Diante dessa problemática, este trabalho teve como objetivo avaliar, do ponto de vista laboratorial, o potencial contaminante da vinhaça quando aplicada na dosagem calculada pela Norma P 4.231 da CETESB (2015) e em dosagens superiores. Para tanto, foram realizados ensaios de percolação em colunas com amostras de solo residual da Formação Rio Claro previamente infiltradas com diferentes doses de vinhaça, permitindo, assim, a análise do efeito de cada dosagem nos parâmetros hidráulicos do solo estudado, bem como, na possível geração de diferentes graus de contaminação do percolado. Face ao exposto, com o desenvolvimento dessa pesquisa, pretende-se contribuir no estabelecimento de critérios para a avaliação de dosagens máximas permitidas visando à proteção de águas superficiais e subterrâneas e, com isso, auxiliar no entendimento e no gerenciamento do uso e da aplicação da vinhaça nos solos.

\section{MATERIAL E MÉTODOS}

Os experimentos foram realizados no Laboratório de Remediação de Áreas Impactadas por Hidrocarbonetos (LRAIH) - Universidade Estadual Paulista (UNESP) - Rio Claro-SP e consistiram em testes de Percolação em Colunas de Solo em meio saturado preparadas com diferentes doses de vinhaça.

A amostra do solo estudado, classificado por Prado, Oliveira e Almeida (1981) como Latossolo Vermelho-Amarelo (LVA), é proveniente da cobertura de material inconsolidado da Formação Rio Claro e foi coletada em um afloramento localizado dentro da área do novo Fórum Trabalhista do município de Rio Claro-SP. (Figura 1).

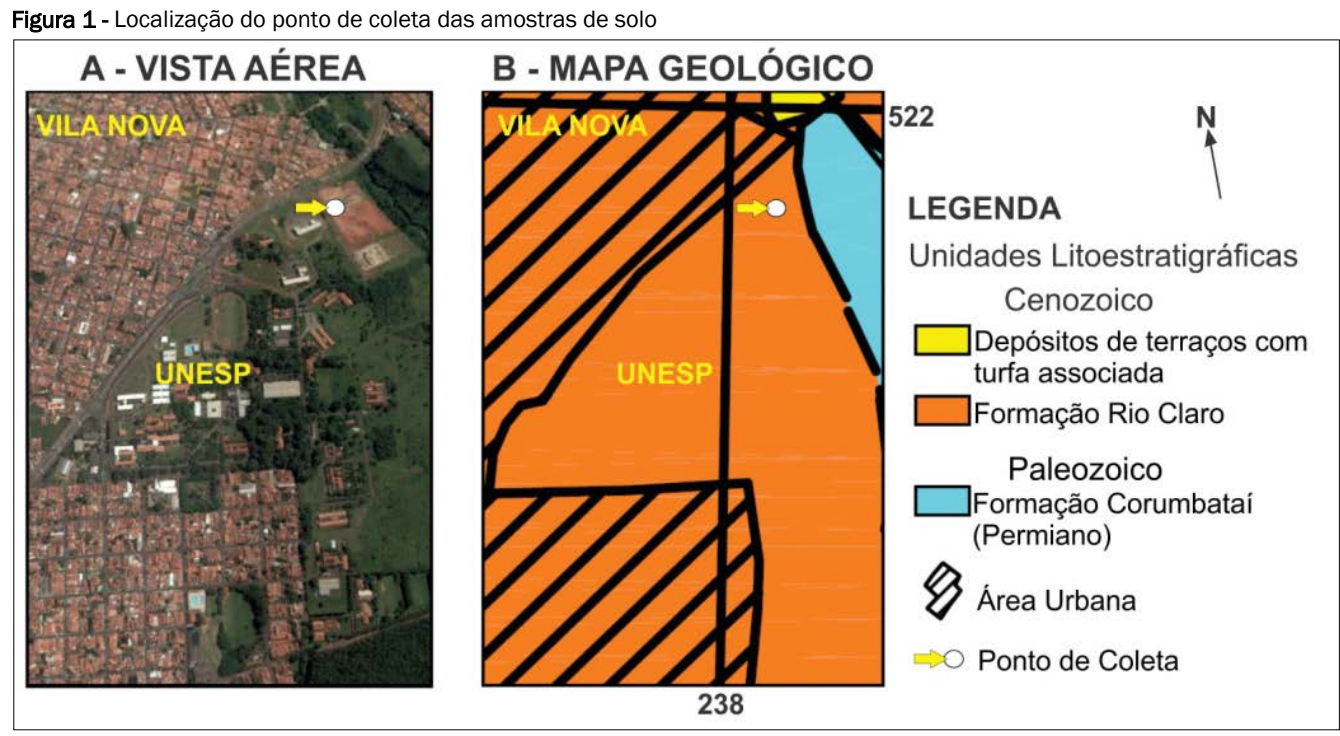

Fonte: A - Vista área Google Earth (em 02/10/2017) e B - Mapa Geológico alterado de Zaine (1994)

Para conhecimento da amostra e preparo das colunas, foram realizadas a determinação da mineralogia dos argilominerais e a caracterização físico-química do solo da Formação Rio Claro. Objetivandose que os ensaios fossem realizados em condições próximas dasnaturais, definiu-se que os corpos de prova compactados (em conformidade com a ABNT NBR 7182, 2016) teriam valores de umidade natural e de massa específica seca aparente próximos aos valores de campo.

A vinhaça utilizada, fornecida por uma usina de açúcar e álcool localizada na cidade de Araras (SP), foi armazenada em frasco de polipropileno escuro e mantida refrigerada em torno $2^{\circ} \mathrm{C}$ para evitar a proliferação de fungos. O equipamento utilizado para a percolação (Figura 2), construído por Basso, Soto e Chang (2017), foi adaptado para a realização da pesquisa.

Os ensaios foram realizados em triplicatas, onde as amostras utilizadas $(19,00 \mathrm{~cm}$ de altura e $6,60 \mathrm{~cm}$ de diâmetro) apresentaram volume de vazios de aproximadamente $295 \mathrm{~cm}^{3}$ (obtido a partir da porosidade do solo e do volume total da coluna). Os testes foram conduzidos em sala mantida climatizada a $20( \pm 5){ }^{\circ} \mathrm{C}$ com a finalidade de evitar alterações dos resultados pela variação térmica e atividade biológica nos fluidos e amostras. 


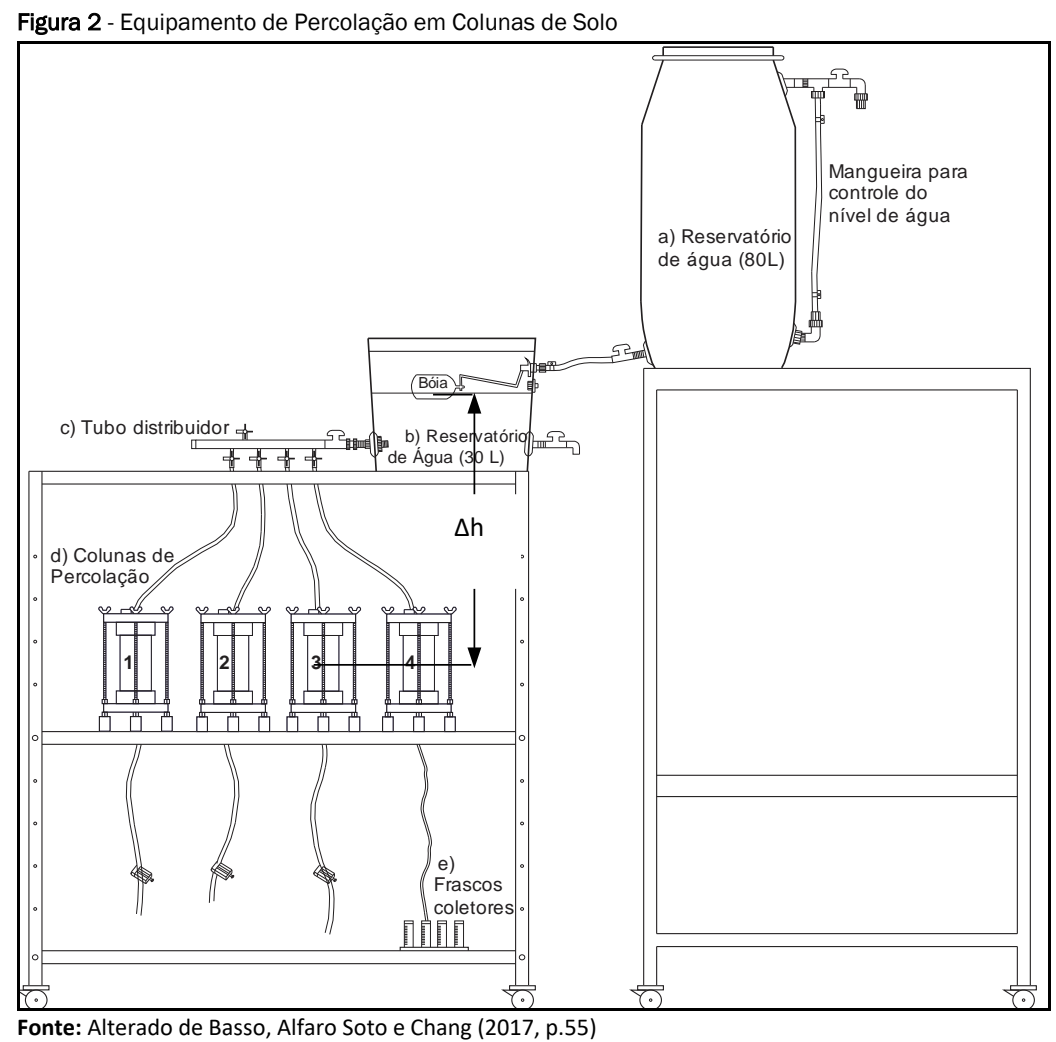

As dosagens aplicadas em cada coluna (Tabela 1) representaram porcentagens da dosagem máxima $\left(\mathrm{m}^{3} / \mathrm{ha}\right.$ ) obtida segundo a Norma Técnica P 4.231 da CETESB (2015), por meio da Equação (1), que calcula a dosagem máxima de vinhaça a ser aplicada no tratamento de solos agrícolas com cultura de cana-de-açúcar.

$$
\frac{\mathrm{m}^{3} \mathrm{de} \text { vinhaça }}{\mathrm{ha}}=\frac{\left[\left(0,05 \times \mathrm{CTC}-\mathrm{K}_{\mathrm{S}}\right) \times 3744+185\right]}{\mathrm{K}_{\mathrm{vi}}}
$$

sendo que 0,05 representa 5\% da Capacidade de Troca Catiônica (CTC) que é expressa em cmolc/dm³; $\mathrm{K}_{\mathrm{s}}$ é a concentração de potássio no solo, expressa em $\mathrm{cmolc} / \mathrm{dm}^{3}$, à profundidade de 0 a 0,80 metros; 3744 é a constante para transformar os resultados da análise de fertilidade expressa em cmolc/ $\mathrm{dm}^{3}$ ou $\mathrm{meq} / 100 \mathrm{~cm}^{3}$ para $\mathrm{kg}$ de potássio em um volume de 01 (um) hectare por 0,80 metros de profundidade; 185 é a massa, em $\mathrm{kg}$, de $\mathrm{K}_{2} \mathrm{O}$ extraído pela cultura por hectare, por corte; e $\mathrm{K}_{\mathrm{vi}}$ é a concentração de potássio na vinhaça expressa em $\mathrm{kg}$ de $\mathrm{K}_{2} \mathrm{O} / \mathrm{m}^{3}$.

Para a obtenção dos valores de $\mathrm{K}_{\mathrm{vi}}, \mathrm{K}_{\mathrm{s}}$ e CTC, as amostras de vinhaça e de solo foram previamente analisadas no laboratório do Departamento de Ciência do Solo da ESALQ - USP que utiliza da metodologia de análise de solo do Instituto Agronômico - IAC, conforme solicitação da norma técnica.

A aplicação da vinhaça nas colunas de solo foi realizada diretamente com o uso de seringa descartável. Após a aplicação, cada coluna ficou um período de 24 horas no dessecador submetido a vácuo para a homogeneização da umidade por capilaridade. Na sequência, a saturação da amostra foi realizada com água submetida a fluxo ascendente (entrada da água na coluna pela base Figura 2), durante um período de 48 horas.

Os ensaios foram realizados sob condição atmosférica, carga constante e meio saturado. 0 procedimento de percolação consistiu na percolação de água deionizada (em fluxo descendente) correspondente a um total de dois volumes de vazios, sendo que o primeiro volume (To) foi percolado imediatamente após a saturação da coluna e o segundo volume ( $\left.T_{31}\right)$ foi percolado após 31 dias, de modo que o corpo de prova tivesse 31 dias de incubação. Durante o período de incubação as colunas foram mantidas na mesma posição.

\begin{tabular}{cccc} 
Tabela 1 - Doses de vinhaça - calculadas conforme a norma P4.231, CETESB (2015) \\
\hline Ensaio & Coluna & $\begin{array}{c}\text { (\%) da Dose } \\
\text { máxima }\end{array}$ & Volume $\left(\mathrm{m}^{3} / \mathrm{ha}\right)$ \\
\hline 1 a 3 & C1 & 100 & Testemunho \\
2 e 3 & C2 & 145 & $85^{(1)}$ \\
1 & C2 & 725 & $80^{(2)}$ \\
1 a 3 & C3 & 1450 & $400(3)$ \\
1 a 3 & C4 & $800^{(3)}$
\end{tabular}

(1)Dose ensaiada em duplicata - equivale a dose máxima permitida pela norma P4.231 da CETESB (2015). (2)Dose ensaiada uma única vez.(3)Dose ensaiada em triplicata.

Para a realização de medidas de potencial hidrogeniônico $(\mathrm{pH})$, potencial de óxido-redução (Eh) e condutividade elétrica (CE), bem como a realização do cálculo da condutividade hidráulica saturada (K), foram coletadas alíquotas de volume conhecido e tempo cronometrado. Ao final do ensaio de cada coluna, todas as alíquotas foram unidas, homogeneizadas e enviadas para análises laboratoriais. Além das análises dos efluentes percolados em To e T31 (vinhaça efluente), para cada ensaio foi coletada uma amostra da vinhaça in natura (vinhaça influente) utilizada no preparo das colunas.

As análises químicas quantitativas das amostras coletadas durante a percolação foram efetuadas no Laboratório de Hidrogeologia e Hidroquímica da UNESP - Rio Claro-SP. As análises do potássio e do sódio foram realizadas em conformidade com a Standard Methods for the Examination of Water and Wastewater - Método 3120B 
(SMEWW, 2017); as análises dos demais íons foram realizadas em conformidade com a United States Environmental Protection Agency - Método 300.0 (US EPA,1993) e Método 300.1 (US EPA, 1997).

Os valores de condutividade hidráulica foram calculados por meio do uso da equação de Darcy (FREEZE; CHERRY,1979) e feitos considerando o gradiente hidráulico imposto pela carga hidráulica correspondente à altura $\Delta \mathrm{h}$ (obtida entre a cota do nível de água no reservatório de 30 litros até o centro da coluna de percolação, $\mathrm{Fi}$ gura 2) e o comprimento da coluna. Para corrigir o efeito da temperatura sobre a viscosidade, os valores obtidos para condutividade hidráulica saturada $(\mathrm{K})$ foram referenciados à temperatura de $20^{\circ} \mathrm{C}\left(\mathrm{K}_{20}\right)$.

\section{RESULTADOS E DISCUSSÕES}

\subsection{Condutividade Hidráulica Saturada}

Com o objetivo de avaliar uma eventual redução da condutividade hidráulica saturada em função do incremento da dosagem de vinhaça, no presente item, serão apresentados os valores médios da condutividade hidráulica a $20^{\circ} \mathrm{C}\left(\mathrm{K}_{20}\right.$ média). Isso posto, a Figura 3 apresenta os valores da $\mathrm{K}_{20}$ média obtidos, no primeiro e no segundo volume percolado ( $\mathrm{T}_{0}$ e $\mathrm{T}_{31}$, respectivamente), para as diferentes doses de vinhaça.

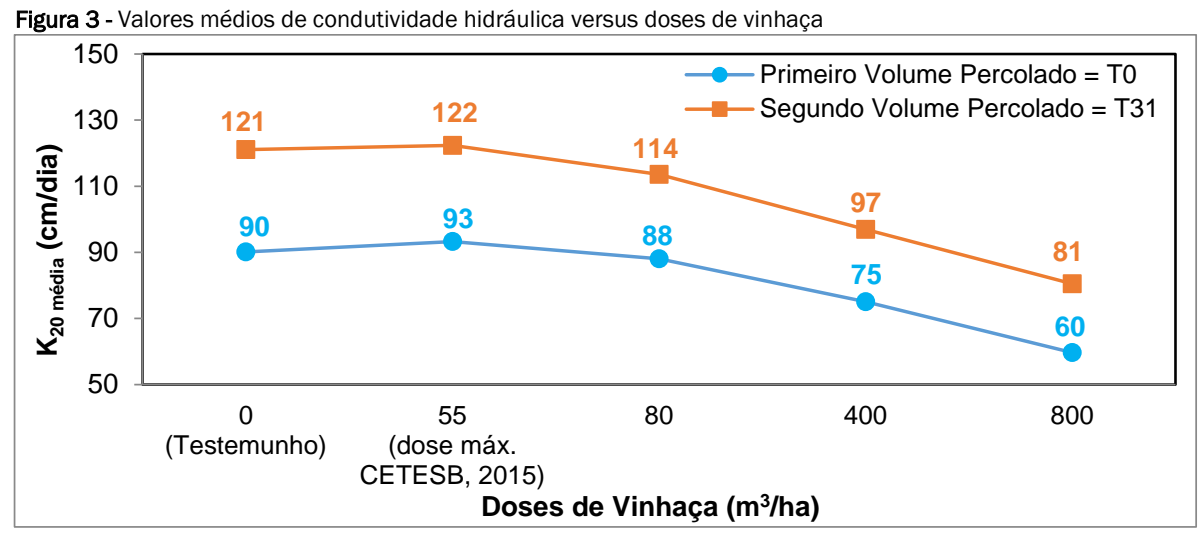

A partir da análise da Figura 3, observa-se que, em $T_{0}$ e em $T_{31}$, os valores de $\mathrm{K}_{20}$ média obtidos para a coluna testemunho e para a coluna com a dose de $55 \mathrm{~m}^{3} /$ ha (que equivale à dose máxima permitida pela norma P 4.231 da CETESB - 2015) foram muito próximos. No entanto, com o incremento das doses aplicadas, houve uma redução progressiva dos valores de condutividade hidráulica saturada. Assim, avaliando os valores de $\mathrm{K}_{20}$ média (obtidos em $\mathrm{T}_{0}$ e $\mathrm{T}_{31}$ ) para as dosagens de 80,400 e $800 \mathrm{~m}^{3} / \mathrm{ha}$, constatou-se que esses valores foram, em média, 4,2\%, 18,3\% e 33,6\%, respectivamente, inferiores aos valores obtidos na coluna testemunho.

Os decréscimos de condutividade hidráulica com o incremento das doses de vinhaça, já observados por outros autores (LOBATO; LIBARDI; CAMARGO, 1998), podem ser atribuídos ao entupimento dos poros gerado em parte pela atividade microbiana e, principalmente, pela acumulação de sólidos em suspensão na solução do solo (MIYAMOTO; KAMEYAMA; NAKAJIMA, 2012). Além disso, segundo Ribeiro, Novais e Bahia Filho (1983), em solo de textura média, a vinhaça atua como dispersante, o que corrobora os resultados obtidos para o solo arenoso da Formação Rio Claro. Fenômenos similares também foram encontrados em testes com solo da Formação Rio Claro por Basso, Alfaro Soto e Chang (2017), onde as amostras sofreram redução da condutividade hidráulica durante o período do experimento.
Adicionalmente, ainda na Figura 3, observa-se que em todas as colunas ensaiadas a condutividade hidráulica foi maior no segundo volume percolado. Uma possível explicação para esse aumento médio de $31,7 \%$ é devido à diluição gerada pela lixiviação de íons e, também, pelo rearranjo das partículas com consequente redistribuição do tamanho de poros, efeitos esses, causados pela percolação do primeiro volume de vazios.

\subsection{Avaliação da Mobilidade de Íons da Vinhaça no Solo}

As caracterizações físico-químicas e mineralógicas do solo da Formação Rio Claro foram executadas visando o preparo das colunas para a realização dos ensaios. Os resultados obtidos, apresentados na Tabela 2, foram utilizados para a compactação das colunas e para o cálculo das dosagens, feito com a Equação (1). Nesse cálculo, foi utilizado o valor de potássio na vinhaça $\left(\mathrm{K}_{\mathrm{vi}}\right)$ equivalente a $7,9 \mathrm{Kg}$ de $\mathrm{K}_{2} \mathrm{O} / \mathrm{m}^{3}$.

Objetivando a avaliação da mobilidade de íons da vinhaça no solo estudado, foram realizadas análises químicas de amostra de solo in natura e de solo retirado das colunas após a percolação de To e $T_{31}$, cujos resultados estão apresentados na Tabela 3. Salienta-se que essas análises não foram executadas em triplicata. 
Tabela 2 - Caracterização físico-química e mineralógica do solo da Formação Rio Claro

\begin{tabular}{|c|c|c|c|c|c|}
\hline $\begin{array}{l}\text { Parâmetro(1) e } \\
\text { Unidade }\end{array}$ & & Valores & Parâmetro & Unidade & Valores \\
\hline Argila & $\%$ & 24,00 & Umidade natural, $\mathrm{W}_{\text {nat }}$ & $\%$ & 8,10 \\
\hline Silte & $\%$ & 12,67 & Massa específica dos sólidos, $\rho_{\mathrm{s}}^{(2)}$ & $\mathrm{g} / \mathrm{cm}^{3}$ & 2,65 \\
\hline Areia Fina & $\%$ & 37,00 & Massa específica seca, $\rho_{\mathrm{d}}^{(3)}$ & $\mathrm{g} / \mathrm{cm}^{3}$ & 1,44 \\
\hline Areia Média & $\%$ & 23,12 & Capacidade de Troca Catiônica, CTC(4) & $\mathrm{cmolc} / \mathrm{dm}^{3}$ & 1,94 \\
\hline Areia Grossa & $\%$ & 2,44 & Potássio no solo, $K_{s}(4)$ & $\mathrm{cmolc} / \mathrm{dm}^{3}$ & 0,03 \\
\hline Pedregulho Fino & $\%$ & 0,78 & Mineralogia da fração fina(5) - Caulinita, & quartzo & \\
\hline
\end{tabular}

Onde: Argila (<0.002 mm), Silte (0,002 a 0,06 mm), Areia Fina (0,06 a 0,2 mm), Areia Média (0,2 a 0,6 mm), Areia Grossa (0,6 a $2 \mathrm{~mm})$ e Pedregulho Fino (2 a 4,8 mm). Metodologias utilizadas: (1)ABNT NBR-7181:2016; (2)Método do Picnômetro; (3)Procedimentos EMBRAPA (2011); (4)Realizadas utilizando-se da metodologia de análise de solo do Instituto Agronômico apresentadas em Raij et all. (2001); e (5)Difração de raios X pelo Método do Pó.

Tabela 3 - Caracterização química do solo (in natura e após os ensaios de percolação)

\begin{tabular}{|c|c|c|c|c|c|c|c|c|c|c|c|c|c|c|c|}
\hline \multicolumn{2}{|c|}{ Parâmetro e Unidade } & \multicolumn{6}{|c|}{ Dose (m³/ha) } & \multicolumn{2}{|c|}{ Parâmetro e } & \multicolumn{6}{|c|}{ Dose $\left(m^{3} / h a\right)$} \\
\hline $\mathrm{pH}$ & - & $\begin{array}{l}\mathbf{O}^{(1)} \\
5,0\end{array}$ & $\begin{array}{l}0^{(2)} \\
4,7\end{array}$ & $\begin{array}{r}55^{(3)} \\
4,7\end{array}$ & $\begin{array}{r}80 \\
4,8\end{array}$ & $\begin{array}{r}400 \\
4,9\end{array}$ & $\begin{array}{r}800 \\
5,2\end{array}$ & $\mathrm{MO}$ & $\mathrm{g} / \mathrm{dm}^{3}$ & $\begin{array}{r}0 \text { (1) } \\
<3,5\end{array}$ & $\begin{array}{l}0(2) \\
4,0\end{array}$ & $\begin{array}{r}5^{(3)} \\
4,0\end{array}$ & $\begin{array}{r}80 \\
3,0\end{array}$ & $\begin{array}{r}400 \\
7,0\end{array}$ & $\begin{array}{r}800 \\
6,0\end{array}$ \\
\hline K & $\mathrm{mmolc} / \mathrm{dm}^{3}$ & 0,3 & $<0,9$ & $<0,9$ & $<0,9$ & 2,7 & 3,5 & $\mathrm{P}$ & $\mathrm{mg} / \mathrm{dm}^{3}$ & 1,0 & $<3$ & $<3$ & $<3$ & $<3$ & $<3$ \\
\hline $\mathrm{Ca}$ & $\mathrm{mmolc} / \mathrm{dm}^{3}$ & $<3$ & 3,0 & 3,0 & 2,0 & 5,0 & 3,0 & $\mathrm{~S}$ & $\mathrm{mg} / \mathrm{dm}^{3}$ & 5,0 & $<6$ & $<6$ & $<6$ & 9,0 & 11,0 \\
\hline $\mathrm{Mg}$ & $\mathrm{mmolc} / \mathrm{dm}^{3}$ & $<1,0$ & $<0,8$ & 1,0 & $<0,8$ & 1,0 & 1,0 & v & $\%$ & 18,0 & 25,0 & 32,0 & 21,0 & 47,0 & 44,0 \\
\hline $\mathrm{Al}$ & $\mathrm{mmolc} / \mathrm{dm}^{3}$ & $<1$ & $<2$ & $<2$ & $<2$ & $<2$ & $<2$ & $\mathrm{~m}$ & $\%$ & 23,0 & 0,0 & 0,0 & 0,0 & 0,0 & 0,0 \\
\hline $\mathrm{H}+\mathrm{Al}$ & $\mathrm{mmolc} / \mathrm{dm}^{3}$ & 16,0 & 10,0 & 10,0 & 10,0 & 10,0 & 10,0 & PST & $\%$ & 1,0 & 2,0 & 1,0 & 2,0 & 1,0 & 1,0 \\
\hline $\mathrm{Na}$ & $\mathrm{mmolc} / \mathrm{dm}^{3}$ & $<0,3$ & $<0,3$ & $<0,3$ & $<0,3$ & $<0,3$ & $<0,3$ & $\mathrm{~N}_{\text {total }}$ & $\mathrm{mg} / \mathrm{kg}$ & 469,0 & 266,0 & 238,0 & 343,0 & 322,0 & 343,0 \\
\hline SB & $\mathrm{mmolc} / \mathrm{dm}^{3}$ & 3,4 & 3,4 & 4,7 & 2,7 & 8,8 & 7,7 & $\mathrm{~N}-\mathrm{NH}_{4}$ & $\mathrm{mg} / \mathrm{kg}$ & 49,0 & 119,0 & 168,0 & 158,0 & 140,0 & 154,0 \\
\hline СТС & $\mathrm{mmolc} / \mathrm{dm}^{3}$ & 19,4 & 13,4 & 14,7 & 12,7 & 18,8 & 17,7 & $\mathrm{~N}-\mathrm{NO}_{3}$ & $\mathrm{mg} / \mathrm{kg}$ & 28,0 & 39,0 & 63,0 & 46,0 & 46,0 & 53,0 \\
\hline
\end{tabular}

(1)Solo in natura (sem ensaiar); (2)Solo ensaiado na coluna sem aplicação de vinhaça (testemunho); e (3)Equivalente à dose máxima permitida pela norma P4.231 da CETESB (2015). MO - Matéria Orgânica; H+Al - Acidez potencial; SB - Soma de bases trocáveis; CTC: Capacidade de troca de cátions; V Saturação da CTC por bases; $m$ - Saturação por Alumínio; e PST - Ponto de saturação total.

Conforme dados das Tabelas 2 e 3, o solo arenoso da Formação Rio Claro apresenta mineralogia caulinítica, com presença de gibbsita e quartzo e caracteriza-se por ser um solo distrófico, ácido, com reduzido teor de matéria orgânica, média CTC e baixas concentrações de bases trocáveis e alumínio; essas baixas concentrações indicam que a maior parte das cargas elétricas da CTC está ocupada pelo íon $\mathrm{H}^{+}$.

Na Tabela 3, comparando os resultados das amostras coletadas das colunas ensaiadas com os resultados da amostra de solo in natura, tem-se que, para a coluna testemunho e para as colunas com as doses de 55 e $80 \mathrm{~m}^{3} /$ ha houve uma queda média de $29,9 \%$ nos valores de CTC, enquanto que, para as doses de 400 e $800 \mathrm{~m}^{3} / \mathrm{ha}$, essa queda foi de $3,1 \%$ e $8,8 \%$, respectivamente. Com a aplicação das doses de 400 e $800 \mathrm{~m}^{3} /$ ha, houve incremento nas concentrações de matéria orgânica, no entanto, os valores obtidos foram inferiores aos detectados na amostra de solo in natura. Quanto ao $\mathrm{N}_{\text {total, }}$, todas as amostras ensaiadas apresentaram queda em sua concentração, sendo a queda mais acentuada na coluna testemunho e na coluna com a dose de $55 \mathrm{~m} 3 /$ ha. Para $\mathrm{N}-\mathrm{NH}_{4}$ e $\mathrm{N}-\mathrm{NO}_{3}$, notou-se aumento de suas concentrações em todas as amostras coletadas das colunas ensaiadas, sendo menos proeminente para o N-NO $\mathrm{N}_{3}$, visto que, em ambiente saturado (predomínio de condição anaeróbica), o nitrato é transformado por denitrificação.

Nessa Tabela 3, notou-se ainda que, as concentrações obtidas para o alumínio, sódio e fósforo apresentaram-se abaixo do limite de quantificação em todas as doses ensaidas. Com a aplicação das doses de 400 e $800 \mathrm{~m}^{3} / \mathrm{ha}$, comparando com o solo in natura, houve um aumento das concentrações de potássio (9,0 e 11,7 vezes, respectivamente), enxofre (1,8 e 2,2 vezes, respectivamente) e cálcio (1,7 e 1,0 vezes, respectivamente).

Conforme os dados apresentados, com o incremento das doses de vinhaça, os acréscimos da concentração de potássio $\left(\mathrm{K}^{+}\right)$no solo foram, consideravelmente, maiores que os observados para o cálcio $\left(\mathrm{Ca}^{+2}\right)$ e magnésio $\left(\mathrm{Mg}^{+2}\right)$. Esse comportamento não era o esperado, dado que íons bivalentes têm preferência na adsorção aos colóides do solo. Brito e Rolim (2005), em ensaios com a aplicação de doses de 0 m³/ha, 500 e 1000 m³/ha em Espodossolo Cárbico, atribuiu esse comportamento do potássio à sua elevada concentração na vinhaça, que gerou um aumento de sua concentração na solução do solo, Ihe favorecendo na competição por um local nos sítios de troca, provocando uma maior adsorção de potássio. Adicionalmente, Basso, Alfaro Soto e Chang (2017) em ensaios laboratoriais de percolação de vinhaça em solo arenoso da Formação Rio Claro, baseado nos resultados do fator de retardamento $(R)$, obtiveram que a ordem de adsorção foi $\mathrm{K}^{+}>\mathrm{Ca}^{2+}>\mathrm{Mg}^{2+}$ corroborando com os resultados obtidos na presente pesquisa.

Quanto ao pH, conforme a Tabela 3, foi possível constatar um declínio de 5,0 para 4,7 nos valores obtidos na amostra de solo in natura para as amostras coletadas das colunas ensaiadas com as doses de 0 e $55 \mathrm{~m}^{3} / \mathrm{ha}$. Nas demais colunas ensaiadas, observou-se um aumento moderado dos valores de $\mathrm{pH}$ com o incremento das doses de vinhaça, sendo mais proeminente na dose de $800 \mathrm{~m}^{3} /$ ha que apresentou valor de 5,2. Esse aumento de $\mathrm{pH}$ era previsto, pois a vinhaça aplicada nos solos promove o seu aumento e isto ocorre devido a oxidação da matéria orgânica do solo feita pela atividade microbiana (MATTIAZZO e GLÓRIA, 1987). 


\subsection{Avaliação da Mobilidade de Íons da Vinhaça nos Efluentes Per- colados}

Com o objetivo de avaliar a mobilidade de íons da vinhaça com a aplicação das doses ensaiadas, no presente item, serão apresentados os valores médios obtidos para as medidas dos parâmetros fí- sico-químicos, bem como, os valores médios dos resultados analíticos das concentrações dos íons presentes na vinhaça aplicada e nas amostras de efluentes percolados. Dessa forma, a Tabela 4 apresenta os valores médios dos parâmetros físico-químicos das amostras de vinhaça e dos efluentes (de $T_{0}$ e $T_{31}$ ) enviadas para análises químicas.

Tabela 4 - Parâmetros físico-químicos das amostras de vinhaça in natura e dos efluentes

\begin{tabular}{|c|c|c|c|c|c|c|c|c|c|c|c|c|}
\hline \multirow{3}{*}{ Parâmetro } & \multirow{3}{*}{ Unidade } & \multirow{3}{*}{$\begin{array}{c}\text { Vinhaça in } \\
\text { natura }\end{array}$} & \multicolumn{10}{|c|}{ Efluente Percolado (dose de vinhaça $\mathrm{m}^{3} / \mathrm{ha}$ ) } \\
\hline & & & \multicolumn{5}{|c|}{ Primeiro Vol. Percolado $=T_{0}$} & \multicolumn{5}{|c|}{ Segundo Vol. Percolado $=T_{31}$} \\
\hline & & & 0 & $55(1)$ & $80(2)$ & 400 & 800 & 0 & $55(1)$ & $80(2)$ & 400 & 800 \\
\hline $\mathrm{pH}$ & $(-)$ & 4,6 & 4,4 & 4,7 & 4,6 & 4,3 & 4,6 & 5,4 & 5,2 & 5,4 & 4,3 & 5,3 \\
\hline Eh & $\mathrm{mV}$ & 198,7 & 344,7 & 320,0 & 335,0 & 342,3 & 303,3 & 253,3 & 214,5 & 225,0 & 150,7 & 48,3 \\
\hline
\end{tabular}

(1)Dose ensaiada em duplicata - equivale a dose máxima permitida pela norma P4.231 da CETESB (2015). (2)Dose ensaiada uma única vez. (3)Os resultados de sólidos totais dissolvidos (STD) são correspondentes aos valores de sólidos parciais dissolvidos dado que não foram feitos todos os elementos, como exemplo, faltou a alcalinidade $\left(\mathrm{HCO}_{3}\right)_{(4)}^{(4)}$ valor de Intervenção (VI) para águas subterrâneas estabelecido pela DECISÃO DE DIRETORIA Nº 256/2016/E da CETESB (2016) para STD é de $1000 \mathrm{mg} / \mathrm{L}$.

xx,xx = Valor igual ou superior ao VI da CETESB (2016). pH= Potencial Hidrogeniônico; Eh - Potencial de Oxirredução; e CE - Condutividade Elétrica.

Os parâmetros organizados na Tabela 4 mostram que no primeiro volume percolado os valores de $\mathrm{pH}$ obtidos nos efluentes da coluna testemunho e nos efluentes das colunas com as doses de 55, 80 e $800 \mathrm{~m}^{3} /$ ha foram ácidos e ficaram entre 4,4 e 4,7, sendo que o menor valor foi obtido na coluna testemunho, estando mais ácido que o da vinhaça in natura $(\mathrm{pH}=4,6)$. No entanto, após os 31 dias de incubação, no segundo volume percolado houve um incremento nos valores de $\mathrm{pH}$ que passaram a oscilar entre 5,2 e 5,4. Na coluna com $400 \mathrm{~m}^{3} /$ ha o $\mathrm{pH}$ teve comportamento anômalo, visto que, apresentou o valor mais baixo de todos $(\mathrm{pH}=4,3)$ e se manteve igual em $T_{0}$ e $T_{31}$

Conforme esperado, na Tabela 4, os dados de condutividade elétrica e de sólidos totais dissolvidos apresentaram comportamentos similares. Isto pode ser explicado pelo fato de que o aumento na concentração dos sólidos totais dissolvidos é resultado da lixiviação dos constituintes da vinhaça para a água, o que gera um aumento da condutividade elétrica, conferindo a água, um caráter condutor. Quanto aos valores de Eh, durante os ensaios não foram detectados valores negativos, indicando condições oxidantes.

A Figura 4 apresenta os valores médios das massas equivalentes dos sólidos totais dissolvidos presentes nas doses de vinhaça aplicadas em cada coluna e nos seus efluentes correspondentes. Também são apresentadas as porcentagens de retenção dos STD nas colunas após os dois volumes percolados (em To e T31), calculadas com base na estimativa das massas existentes em cada coluna ensaiada.

Figura 4 - Valores médios da massa equivalente dos sólidos totais dissolvido (mg) na vinhaça influente de cada coluna e nos seus respectivos efluentes $\left(T_{0}\right.$ e $\left.T_{31}\right)$

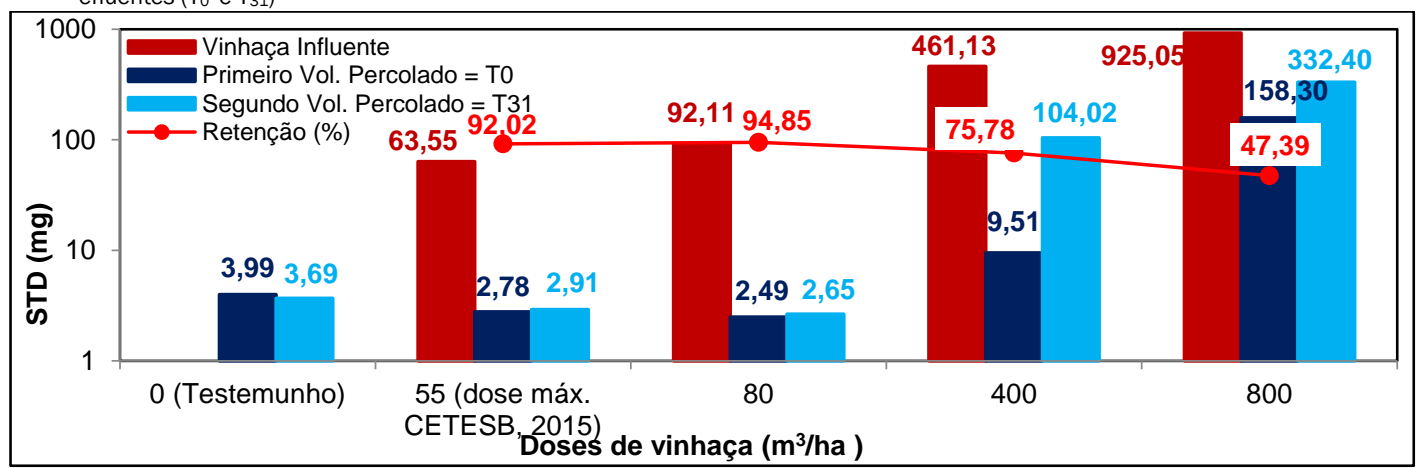

A avaliação conjunta da Figura 4 com a Tabela 4 mostra que nas colunas com aplicação das doses de 55 e $80 \mathrm{~m}^{3} / \mathrm{ha}$, e consequente aporte de 63,55 e $92,11 \mathrm{mg}$ de STD, respectivamente, os efluentes percolados apresentaram valores de CE e STD em média $28,5 \%$ inferiores aos obtidos na coluna testemunho, indicando que a aplicação dessas doses possivelmente aumentou a capacidade de retenção do solo.

A Tabela 5 apresenta os valores médios das concentrações dos parâmetros analisados nas amostras de vinhaça in natura (aplicada nos ensaios) e nos efluentes percolados das colunas, coletados em
$T_{0}$ e $T_{31}$. Nessa tabela, os resultados foram comparados com os Valores Máximos Permitidos (VMP) dos padrões de potabilidade estabelecidos pela Portaria de Consolidação No 5 (MINISTÉRIO DA SAÚDE, 2017) e com os Valores de Intervenção para Águas Subterrâneas estabelecidos pela Decisão de Diretoria No 256/2016/E (CETESB, 2016).

Cátions de interesse (K, Na, Ca e Mg): Em semelhança à Figura 4, a Figura 5 apresenta os valores médios das massas equivalentes dos cátions de interesse versus doses de vinhaça aplicadas. 
Tabela 5 - Composição química da Vinhaça e dos Efluentes Percolados (valores médios)

CONCENTRAÇĀO (mg/L)

\begin{tabular}{|c|c|c|c|c|c|c|c|c|c|c|c|c|}
\hline \multirow{3}{*}{ Parâmetro } & \multirow{3}{*}{$\begin{array}{l}\operatorname{VMP}_{(1)(2)} e \\
\operatorname{VI}^{(3)}\end{array}$} & \multirow{3}{*}{$\begin{array}{c}\text { Vinhaça in } \\
\text { natura }\end{array}$} & \multicolumn{10}{|c|}{ Efluente Percolado (dose de vinhaça $\mathrm{m}^{3} / \mathrm{ha}$ ) } \\
\hline & & & \multicolumn{5}{|c|}{ Primeiro Vol. Percolado $=\mathrm{T}_{0}$} & \multicolumn{5}{|c|}{ Segundo Vol. Percolado $=T_{31}$} \\
\hline & & & 0 & 55 & $80(4)$ & 400 & 800 & 0 & 55 & $80(4)$ & 400 & 800 \\
\hline K & - & 7430,000 & 1,530 & 0,720 & 0,850 & 0,873 & 61,000 & 1,303 & 0,670 & 0,880 & 73,567 & 449,333 \\
\hline $\mathrm{Ca}$ & - & 899,333 & 0,233 & 0,190 & 0,210 & 2,773 & 67,867 & 0,108 & 0,124 & 0,076 & 30,433 & 37,567 \\
\hline $\mathrm{Cl}^{-}$ & $250,0^{(1)}$ & 2678,33 & 1,51 & 0,76 & 0,94 & 8,69 & 310,33 & 1,26 & 0,88 & 0,95 & 180,67 & 238,33 \\
\hline $\mathrm{SO}_{4}^{2-}$ & $250,0^{(1)}$ & 1946,000 & 0,051 & 0,050 & $<0,020$ & 0,047 & 0,227 & 0,073 & 0,060 & 0,061 & 0,133 & 4,590 \\
\hline$P$ & - & 19,533 & 0,007 & 0,006 & $<0,005$ & 0,007 & 0,015 & 0,007 & $<0,005$ & 0,013 & 0,009 & 0,015 \\
\hline Acetato & - & 578,667 & 4,507 & 3,275 & 1,130 & 10,003 & 14,500 & 0,827 & 0,385 & $<0,10$ & 11,420 & 309,667 \\
\hline $\mathrm{NH}_{4}^{+}$ & - & NA & 0,080 & 0,070 & $<0,050$ & 0,260 & 3,114 & 0,507 & 0,345 & 0,350 & 6,613 & 8,013 \\
\hline $\mathrm{N}\left(\mathrm{NO}_{2}\right)$ & $1,0^{(2)}$ & $<0,006$ & $<0,006$ & $<0,006$ & $<0,006$ & $<0,006$ & $<0,006$ & 0,007 & 0,017 & 0,008 & $<0,006$ & $<0,006$ \\
\hline $\mathrm{N}\left(\mathrm{NO}_{3}\right)$ & $10,0^{(2)(3)}$ & $<0,009$ & 0,043 & 0,047 & 0,047 & 0,463 & 2,683 & 0,047 & 0,016 & 0,056 & 0,093 & $<0,009$ \\
\hline $\mathrm{N}\left(\mathrm{NH}_{4}\right)$ & - & NA & 0,062 & 0,055 & $<0,040$ & 0,204 & 2,420 & 0,393 & 0,270 & 0,270 & 5,137 & 6,223 \\
\hline TOC & - & 10083,33 & 5,93 & 23,00 & 15,90 & 179,33 & 434,67 & 7,42 & 15,50 & 16,40 & 67,43 & 399,33 \\
\hline
\end{tabular}

(1)(2)VMP = Valor Máximo Permitido estabelecido pela Portaria de Consolidação № 5 do MINISTÉRIO DA SAÚDE (2017), onde:(1)VMP - Tabela de padrão organoléptico de potabilidade; (2)VMP - Tabela de padrão de potabilidade para substâncias químicas que representam risco à saúde. (3)VI

= Valor de Intervenção para águas subterrâneas estabelecido pela DECISÃO DE DIRETORIA N²56/2016/E da CETESB (2016). (4)Valores obtidos em um único ensaio.

$x x, x x=$ Valor igual ou superior ao VI CETESB (2016) e/ou VPM Potabilidade (2017).

$<x x, x x=<$ Limite de Quantificação; NA = Não analisado; e TOC = Carbono Orgânico Total. 
Figura 5 - Valores médios das massas equivalentes de $\mathrm{K}$ (a), $\mathrm{Na}$ (b), Ca (c) e Mg (d) na vinhaça influente de cada coluna e nos seus respectivos efluentes de $T_{0}$ e $T_{31}$
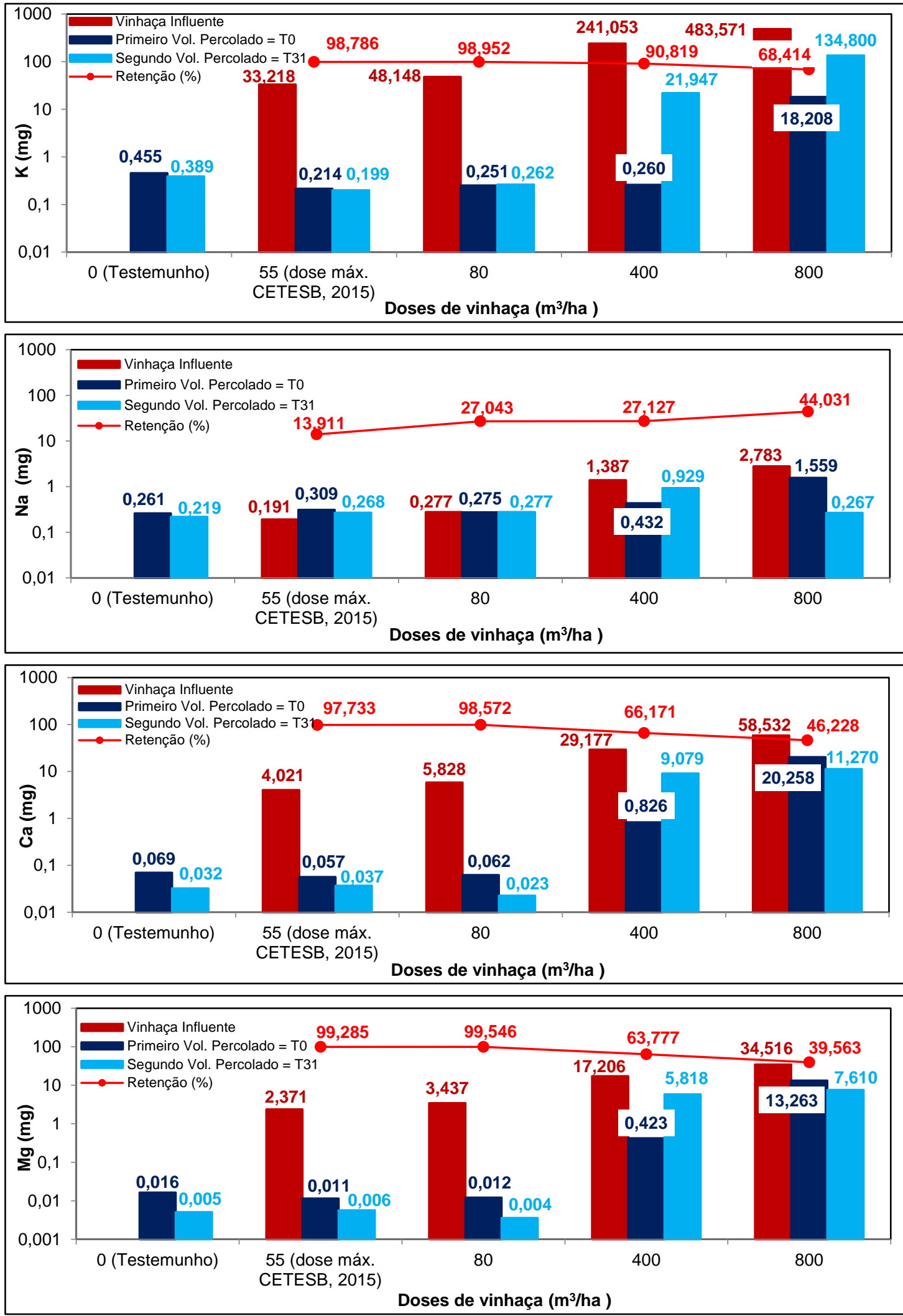

Quanto aos cátions de interesse, a análise da Tabela 5 e da Figura 5 mostra que nos efluentes da coluna testemunho e das colunas com as doses de 55 e $80 \mathrm{~m}^{3} /$ ha, as concentrações obtidas em $\mathrm{T}_{31}$ foram menores que as obtidas em To e que, de uma forma geral, esses cátions apresentaram comportamento similares. Com exceção do sódio, nas colunas com doses de 55 e $80 \mathrm{~m}^{3} / \mathrm{ha}$, o solo da Formação Rio Claro apresentou alta capacidade de retenção (supe- rior a 97,7\%), no entanto, com a aplicação das doses de 400 e 800 $\mathrm{m}^{3} /$ ha ocorreu uma queda progressiva nessa capacidade.

Na coluna com a dose de $400 \mathrm{~m}^{3} / \mathrm{ha}$, os incrementos nas taxas de lixiviação de To para $T_{31}$ foram de 2,8 vezes para o sódio, 11,3 vezes para o cálcio, 14,1 para o magnésio e 84,5 para o potássio. Esse comportamento não foi identificado nas demais colunas que, com 
exceção do potássio na coluna de $800 \mathrm{~m}^{3} / \mathrm{ha}$, apresentaram queda nas taxas de lixiviação. Conforme apresentado na Tabela 4, os efluentes coletados da coluna com a dose de $400 \mathrm{~m}^{3} / \mathrm{ha}$ apresentaram valores anômalos de pH, que se mantiveram baixos em $T_{0}$ e $T_{31}, 0$ que pode ter proporcionado uma maior mobilização dos íons.

As baixas taxas de retenção de sódio (Figura $5 b$ ) são explicadas pelo fato de que a vinhaça apresentou baixas concentrações desse cátion (Tabela 5), devido a isso, nas colunas com as doses de 55 e 80 $\mathrm{m}^{3} / \mathrm{ha}$ a soma das massas lixiviadas em To e $T_{31}$ foi maior do que a massa aplicada nessas dosagens indicando que grande parte dessa massa lixiviada trata-se da massa de sódio presente no solo da Formação Rio Claro.

Carbono Orgânico Total (TOC): Conforme dados da Tabela 5, a aplicação de vinhaça gerou aumento nas concentrações de TOC nos percolados de todas as doses ensaiadas, sendo mais acentuado a partir da dose de $400 \mathrm{~m}^{3} / \mathrm{ha}$. As amostras coletadas em To e $T_{31}$ mantiveram o mesmo comportamento, diferenciando apenas pelas concentrações que, em geral, foram mais baixas em $T_{31}$, possivelmente devido à diluição gerada pela lixiviação do primeiro volume de vazios. Hassuda, Rebouças e Cunha (1990), em análises de água subterrânea coletadas em piezômetros instalados em área com solo fertilizado com vinhaça, atribuem que os valores relativamente altos de TOC na água refletem a alta concentração da matéria orgânica na vinhaça.

Cloreto, Sulfato e Fósforo: Na Tabela 5 tem-se que a vinhaça in natura apresentou concentrações de cloreto e sulfato muito superiores aos VMP da "Tabela de Padrão Organoléptico de Pota-bilidade" do Ministério da Saúde (2017). No entanto, nos efluentes das colunas, apenas a amostra coletada em To da coluna com a dose de $800 \mathrm{~m}^{3} /$ ha apresentou teores de cloreto superiores ao seu respectivo VMP. Para o sulfato, todas as amostras de efluentes apresentaram concentrações abaixo dos valores de referência ambiental. Os resultados obtidos para o cloreto e sulfato são corroborados por Hassuda, Rebouças e Cunha (1990), que apresentaram que o cloreto possui característica conservativa que propicia sua transferência quase direta para os aquíferos, enquanto os baixos teores de sulfato podem ser atribuídos ao fato desse íon ter uma forte tendência de formar íons e compostos complexos. Devido ao exposto, Gloeden et al. (1991), assim como Hassuda, Rebouças e Cunha (1990), apresentaram que o cloreto presente na vinhaça impõe risco à qualidade da água subterrânea. Quanto ao fósforo, as concentrações detectadas nas amostras analisadas foram baixas. Segundo Hassuda, Rebouças e Cunha (1990) o fósforo, além de sua baixa concentração na vinhaça, tem uma forte tendência a formar íns pouco solúveis, o que pode justificar sua baixa concentração no percolado.

Nitrito, Nitrato e Amônio: Conforme a Tabela 5, na vinhaça in natura, o amônio não foi avaliado e o nitrito e o nitrato não apresentaram concentrações, no entanto, nos percolados das colunas foram detectadas concentrações de amônio e nitrato em quase todas as amostras coletadas. Essas concentrações, possivelmente, são oriundas do solo da Formação Rio Claro que, conforme a Tabela 3, apresentou altos valores de concentração de nitrogênio total e de $\mathrm{N}-\mathrm{NH}_{4}$ e N-NO . $\mathrm{O}$ nitrito foi detectado em baixas concentrações em $\mathrm{T}_{31}$ nas amostras da coluna testemunho e das colunas com as doses de 55 e 80 m³/ha. Segundo Hassuda, Rebouças e Cunha (1990), em ambientes normais o nitrito é uma forma muito instável e logo é nitrificado para nitrato.
Fluoreto e Acetato: Na vinhaça utilizada não foram detectadas concentrações de Fluoreto (Tabela 5), no entanto, foram detectadas concentrações em quase todas as amostras de percolado das colunas, com destaque para a amostra coletada no segundo volume percolado da coluna com dose de $800 \mathrm{~m}^{3} /$ ha cuja concentração está superior ao VMP da "Tabela de Padrão de Potabilidade para Substâncias Químicas que Representam Risco à Saúde" do Ministério da Saúde (2017). Quanto ao Acetato, foram detectadas concentrações em quase todas as amostras analisadas, estando em teores elevados na amostra de vinhaça e na amostra coletada no segundo volume percolado da coluna com dose de $800 \mathrm{~m}^{3} / \mathrm{ha}$.

\section{CONCLUSÕES}

No gerenciamento do uso e da aplicação da vinhaça em solo com cultura de cana-de-açúcar o estabelecimento de critérios para a avaliação de dosagens máximas permitidas é uma ferramenta primordial para a proteção do solo e das águas superficiais e subterrâneas. Para tanto, o estudo e a compreensão dos efeitos da vinhaça nas propriedades hidráulicas e na mobilidade de íons no solo é uma ferramenta essencial para evolução desses critérios.

Diante dessa perspectiva, com os resultados laboratoriais obtidos na pesquisa, visando a avaliação do potencial contaminante da vinhaça quando aplicada em solo arenoso da Formação Rio Claro na dosagem calculada pela Norma P 4.231 da CETESB (2015) e em dosagens superiores, pode se concluir que:

A aplicação de vinhaça na dose máxima estabelecida não trouxe nenhuma alteração significativa quanto à condutividade hidráulica saturada e apresentou aspectos positivos do ponto de vista ambiental e da fertilidade do solo devido ao aumento na sua capacidade de retenção. Assim, com base nos resultados, pode-se afirmar que a aplicação de vinhaça na dose máxima estabelecida pela CETESB (2015) não apresentaria riscos à qualidade do solo estudado e da água subterrânea. Ressalta-se, ainda, que os resultados com a aplicação da dose máxima permitida e com a aplicação de 1,5 vezes essa dosagem (doses de 55 e $80 \mathrm{~m}^{3} / \mathrm{ha}$, respectivamente) foram muito similares indicando que o atual cálculo é realizado de forma restritiva e segura.

Entretanto, a aplicação de vinhaça em doses equivalentes a 7,3 e 16,4 vezes a dose máxima permitida pela CETESB (2015), que na presente pesquisa corresponderam às doses de 400 e $800 \mathrm{~m}^{3} / \mathrm{ha}$, respectivamente, proporcionou o aumento médio de 10,3 vezes dos teores de potássio no solo. Adicionalmente, conduziu a uma redução gradual dos valores de condutividade hidráulica saturada e gerou uma queda progressiva na capacidade de retenção do solo, que implicou em perdas por lixiviação e consequente aumento nas concentrações de sólidos totais dissolvidos, cloreto, fluoreto, acetato e carbono orgânico total nos lixiviados, que em algumas amostras apresentaram concentrações superiores aos valores de referência ambiental e de potabilidade adotados, podendo, portanto, gerar riscos à qualidade do solo e da água subterrânea tornando-a imprópria para consumo humano.

\section{REFERÊNCIAS}

ABNT. ASSOCIAÇÃO BRASILEIRA DE NORMAS TÉCNICAS. NBR 7181:2016 Versão Corrigida:2017 - Solo - Análise granulométrica. 2. ed., Rio de Janeiro, 2017. 12 p. 
ABNT. ASSOCIAÇÃO BRASILEIRA DE NORMAS TÉCNICAS. NBR 7182:2016 Solo - Ensaio de compactação. 2. ed., Rio de Janeiro, 2016. 9 p.

BASSO, J.B.; ALFARO SOTO, M.A.; CHANG, H.K. Percolação de vinhaça em coluna de solo arenoso da formação Rio Claro. Águas Subterrâneas, 31(1): 52-65, 2017.

BRITO, F. L.; ROLIM. M. M. Comportamento do efluente e do solo fertirrigado com vinhaça. Agropecuária Técnica, Areia-PB, v.26, n.1, p. 60-67, 2005.

CETESB. COMPANHIA AMBIENTAL DO ESTADO DE SÃO PAULO. Decisão de Diretoria No 045/2015/C: Norma Técnica P4.231: Vinhaça - Critérios e procedimentos para aplicação no solo agrícola. 3.ed, 2.versão, 2015. 15 p.

CETESB. COMPANHIA AMBIENTAL DO ESTADO DE SÃO PAULO. Decisão de Diretoria $N^{\circ}$ 256/2016/E: Valores Orientadores para Solos e Águas Subter râneas no Estado de São Paulo. São Paulo, 2016. 5 p.

CONAB. COMPANHIA NACIONAL DE ABASTECIMENTO. Acompanhamento da safra brasileira - Cana-de-açúcar, Safra 2018/19, v. 5, n. 1, primeiro levantamento - maio 2018, 66 p.

EMBRAPA. EMPRESA BRASILEIRA DE PESQUISA AGROPECUÁRIA - SOLOS. Manual de métodos de análise de solo. 2. ed. revista, Rio de Janeiro, RJ, 2011. 230p.

FREEZE, R.A; CHERRY, J.A. Groundwater. Englewood Cliff. Prentice-Hall, 1979. $604 \mathrm{p}$.

GLOEDEN, E.; CUNHA, R. C. A.; FRACCAROLI, M. J. B.; CLEARY, R. W. The be haviour of vinasse constituents in the unsaturated and saturated zones in the Botucatu Aquifer recharge area. Water Science \& Technology, v. 24, n. 11, p. 147-157, 1991.

GLÓRIA, N. A. Utilização agrícola da vinhaça. Brasil Açucareiro, n.5 (p.397), p.11-17, 1975.

HASSUDA, S.; REBOUÇAS, A. DA C.; CUNHA, R. C. DE A. Aspectos qualitativos da infiltração da vinhaça de cana no Aqüífero Bauru. Revista IG, São Paulo, SP, v. 11, n. 2, p.5-20, 1990.

LOBATO, E. J. V.; LIBARDI, P. L.; CAMARGO, O. A. Condutividade hidráulica de amostras remoldadas de um Latossolo Roxo Distrófico tratado com água/vinhaça. R. Bras. Ci. Solo, 22, p.181-188, 1988.
MATTIAZO, M.E.; GLÓRIA, N. A. Effect of vinasse on soil acidity. Water Science \& Technology. Rio de Janeiro, v. 19, n. 7, p.1293-1296, 1987.

MINISTÉRIO DA SAÚDE. Portaria de Consolidação No 5 - Consolidação das normas sobre as ações e os serviços de saúde do Sistema Único de Saúde. Capítulo V - Do Padrão de Potabilidade, 2017. 825 p.

MIYAMOTO, T.; KAMEYAMA, K.; NAKAJIMA, T. Reduction in Saturated and Unsaturated Hydraulic Conductivities of an Andisol by Vinasse Application. Soil Science Society of America Journal, 77, p. 1-7, 2012.

PRADO, H.; OLIVEIRA, J. B.; ALMEIDA, C. L. F. Levantamento Pedológico Semidetalhado do Estado de São Paulo. Quadrícula de São Carlos. Escala 1:100.000. Instituto Agronômico de Campinas, 1981.

RAIJ, B.V.; ANDRADE, J.C.; CANTARELLA, H.; QUAGGIO, J.A. Análise química para avaliação da fertilidade de solos tropicais. Instituto Agronômico de Campinas, Campinas - SP, 2001. 285 p

RIBEIRO, A.C.; NOVAIS, R.F; BAHIA FILHO, A.F.C. Efeitos da vinhaça sobre a dispersão de argila de amostras de latossolos. Revista Ceres, Viçosa-MG, v. 30 , n. 167, p.12-18, 1983.

RODELLA, A.A.; FERRARI, S.E. A composição da vinhaça e efeitos de sua aplicação como fertilizante na cana-de-açúcar. Brasil Açucareiro, n.7 (p.380), p.6-13, 1977.

SMEWW. STANDARD METHODS FOR THE EXAMINATION OF WATER AND WASTEWATER. Method 3120 B - Metals by Plasma Emission Spectroscopy. 23. ed., 2017.

US EPA. United States Environmental Protection Agency. Method 300.0: Determination of inorganic anions by ion chromatography. Revision 21 , Cincinnati, $\mathrm{OH}, 1993$.

US EPA. United States Environmental Protection Agency . Method 300.1: Determination of Inorganic Anions in Drinking Water by Ion Chromatography. Revision 1.0. Cincinnati, OH, 1997.

ZAINE, J. E. Geologia da Formação Rio Claro na Folha Rio Claro (SP). Dissertação (Mestrado) - Curso de Geociências, Instituto de Geociências e Ciências Exatas, Univ. Estadual Paulista, Rio Claro, 1994. 98 p. 